\title{
Corrosion Inhibitory Studies of Novel Schiff Bases Derived from Hydralazine Hydrochloride on Mild Steel in Acidic Media
}

\author{
Romanus N. Njong ${ }^{1}$, Bridget N. Ndosiri ${ }^{2}$, Emmanuel N. Nfor ${ }^{1 *}$, Offiong E. Offiong ${ }^{3}$ \\ ${ }^{1}$ Department of Chemistry, Faculty of Science, University of Buea, Buea, Cameroon \\ ${ }^{2}$ Department of Inorganic Chemistry, Faculty of Science, University of Yaounde 1, Yaounde, Cameroon \\ ${ }^{3}$ Department of Pure and Applied Chemistry, University of Calabar, Calabar, Nigeria \\ Email: *nforemman@gmail.com
}

How to cite this paper: Njong, R.N., Ndosiri, B.N., Nfor, E.N. and Offiong, O.E. (2018) Corrosion Inhibitory Studies of Novel Schiff Bases Derived from Hydralazine Hydrochloride on Mild Steel in Acidic Media. Open Journal of Physical Chemistry, 8, 15-32.

https://doi.org/10.4236/ojpc.2018.81002

Received: January 17, 2018

Accepted: February 23, 2018

Published: February 26, 2018

Copyright $(9) 2018$ by authors and Scientific Research Publishing Inc. This work is licensed under the Creative Commons Attribution International License (CC BY 4.0).

http://creativecommons.org/licenses/by/4.0/

\begin{abstract}
The inhibition performance of 1-hydralazinophthalazine (HPZ) (1), and synthesized1-(2-[(5-methylfuran-2-yl)methylene)] hydrazono) phthalazine (MFHPZ) (2), 1-(phthalazin-1(2H)-one) [(pyridin-2-yl) ethylidene] hydrazone (ACPHPZ) (3) and (2-acetylthiophene hydrazono) phthalazine (ACTHPZ) (4) has been investigated for mild steel in $1 \mathrm{M} \mathrm{HCl}$. Compound 4 shows maximum inhibition efficiency of $93 \%$ at $5.0 \times 10^{-3} \mathrm{M}$ concentration. The evaluation of thermodynamics and activation parameters indicated spontaneous adsorption of the inhibitor molecules which takes place through chemisorption. The adsorption of $\mathbf{3}$ and $\mathbf{2}$ follows Langmuir adsorption isotherm and Temkin adsorption isotherm for $\mathbf{4}$ and $\mathbf{1}$. The inhibitor efficiency was of the order $4>3>1>2$. Impedance study for the representative inhibitor compounds $\mathbf{4}$ and $\mathbf{3}$ showed that decrease in charge transfer resistance is responsible for effective protection of mild steel surface by the tested inhibitor.
\end{abstract}

\section{Keywords}

Mild Steel, Hydralazine Hydrochloride, Weight Loss, Corrosion Inhibition

\section{Introduction}

The corrosion of steel especially in acid medium is the most common form of corrosion and directly impacts its cost and safety [1] [2]. Studies on the prevention of steel corrosion in acidic environments and the problematic chemical processes that arise have attracted the attention of many researchers from a wide range of industrial sectors [3]. The majority of well-known inhibitors are organic 
compounds containing multiple bonds and heteroatoms, such as $\mathrm{O}, \mathrm{N}$ or $\mathrm{S}$, which allow adsorption onto the metal surface [4]. Many researchers have reported that inhibition mainly depends on the physicochemical and electronic properties of the organic inhibitor, which are related to the presence of certain functional groups, steric effects, electronic density of donor atoms and orbital character of donating electrons, etc. [5]. Schiff bases formed by the condensation of amines and carbonyl/aldehyde compounds are potential inhibitors. The greatest advantage of Schiff bases is that they can be conveniently and easily synthesized from relatively cheap starting materials. Due to the presence of imine groups $(>\mathrm{C}=\mathrm{N}-)$ and electronegative nitrogen, sulfur and/or oxygen atoms in the molecule, Schiff bases are effective inhibitors for the corrosion of steel in acidic media [6]. Generally, the tendency to form stronger coordination bonds and, as a result, the inhibition efficiency increases according to the following trend: $\mathrm{O}<\mathrm{N}<\mathrm{S}<\mathrm{P}$ [7]. Moreover, the surface state and excess charge of the metal surface also affect the adsorption behavior of inhibitor molecules on the metal surface. It has also been reported that heterocyclic organic components have better inhibition role in acidic media [8]. Furthermore, as most of the chemical compounds that prevent corrosion of metals and alloys are toxic, and thus pose a threat both to human health and environment, their usage is limited [9]. For this reason, several authors have reported the use of natural products, and drugs as green corrosion inhibitors for various metals and alloys viz. Ketoconazole [10], Tenofovir Disoproxil furmarate [11], Rabeprazole [12], Torsemide and Furosemide [13], Metol [14], Ciprofloxacin [15], Anthranilic acid [16], Metronidazole [17] are reported to be excellent corrosion inhibitors.

In view of the above and in continuation of our previous studies on the synthesis and application of hydalazine hydrochloride based ligands [18] [19] [20] here in we report on detailed investigation on the inhibition behavior of hydralazine hydrochloride (HPZ) and its three derivatives: 1-(2-[(5-methylfuran-2-yl) methylene)] hydrazono) phthalazine (MFHPZ), 1-(phthalazin-1(2H)-one) [(pyridin-2-yl) ethylidene] hydrazone (ACPHPZ), (2-acetylthiophene hydrazono) phthalazine (ACTHPZ), on mild steel in $\mathrm{HCl}$ solution by weight loss, potentiodynamic polarization and electrochemical impedance spectroscopy (EIS) measurements.

\section{Experimental}

\subsection{Synthesis of Inhibitors}

HPZ (1) was used as purchased without further purification.

MFHPZ (2) was prepared by the condensation of 5-methylfufuraldehyde (2.4 $\mathrm{g}, 2.0 \mathrm{mmol})$ and hydralazine hydrochloride $(3.2 \mathrm{~g}, 2.0 \mathrm{mmol})$ in ethanolic solution. A $10-\mathrm{mL}$ sodium acetate $(1.7 \mathrm{~g}, 20 \mathrm{mmol})$ solution was added as a buffering agent. The mixture was refluxed at $60^{\circ} \mathrm{C}$ for $4 \mathrm{hr}$ while stirring. The product was left to cool, vacuum-filtered, rinsed several times with water, ethanol and diethyl ether. It was finally crystallized from ethanol as yellow crystals which were used 
for single crystal X-ray diffraction studies.

ACPHPZ (3) was prepared by mixing equimolar amounts of 2-acetylpyridine (307 mg, $2.54 \mathrm{mmol}$ ), hydralazine hydrochloride (500 mg, $2.54 \mathrm{mmol}$ ) and sodium acetate $(350 \mathrm{mg}, 2.56 \mathrm{mmol}$ ) as a buffering agent in $50 \mathrm{ml}$ ethanol. The mixture was then refluxed at $60^{\circ} \mathrm{C}$ while stirring for $4 \mathrm{hrs}$. The product was left overnight to cool, removed by vacuum filtration; washed several times with water and ethanol to give yellow powder.

ACTHPZ(4) was prepared by the condensation of 2-acetylthiophene (2.6 g, 20 $\mathrm{mmol})$ and hydralazine hydrochloride $(3.2 \mathrm{~g}, 20 \mathrm{mmol})$ in ethanolic solution. A 10 - $\mathrm{mL}$ sodium acetate $(1.7 \mathrm{~g}, 20 \mathrm{mmol})$ solution was added as a buffering agent. The mixture was boiled under reflux at $60^{\circ} \mathrm{C}$ for $4 \mathrm{hr}$ while stirring. The product was left to cool, vacuum-filtered, washed several times with water, ethanol and diethyl ether. It was finally crystallized from ethanol as yellow crystals which were used for single crystal X-ray diffraction studies.

The melting point was determined by a Gallen Kamp melting point apparatus fitted with a thermometer. FTIR spectra were recorded using a Perkin-Elmer Spectrum100 FT-IR Spectrometer using $\mathrm{KBr}$ pellets in the $4000-400 \mathrm{~cm}^{-1}$ range. ${ }^{1} \mathrm{H}$ NMR spectra were recorded on a Varian Unity Plus $400-\mathrm{MHz}$ instrument, while ${ }^{13} \mathrm{C}$ NMR spectra were recorded using a Bruker AV 400-MHz instrument and single $\mathrm{X}$-ray diffraction analysis and structure determination was carried out with a Bruker DUO APEX II CCD diffractometer at $173 \mathrm{~K}$ using an Oxford cryostream-700.

\subsection{Preparation of the Working Electrode}

Rectangular mild steel specimens with composition (wt \%): P 0.045, Si 0.300, Cr 0.300 , Mn $0.300-0.650$, C 0.140-0.220, S 0.050, Ni 0.300, Cu 0.300, and the remainder $\mathrm{Fe}$ were soldered to coated $\mathrm{Cu}$-wires for electrical connections and then mounted in epoxy resin with an exposed area of $1 \mathrm{~cm}^{2}$. Before each experiment, the surface of working electrode was mechanically abraded with emery papers of grades 400 and 800 and then rinsed with distilled water and acetone and dried in warmed air flow. All solvents and chemicals used were of AR grade and used as such without further purification. Doubly distilled water was used in the preparation of various concentrations of test solutions. The $\mathrm{HCl}$ solution was prepared by diluting a concentrated solution (37\%) with distilled water. The concentration range of the inhibitors was varied from $0.63 \times 10^{-4} \mathrm{M}$ to $5 \times 10^{-4} \mathrm{M}$.

\subsection{Weight Loss Measurements}

Rectangular mild steel specimens of dimension $4 \mathrm{~cm} \times 1 \mathrm{~cm} \times 0.1 \mathrm{~cm}$ were first polished using 400 and 800 grit emery paper, washed with distilled water, degreased with acetone, dried and kept in a dessicator. After weighing accurately, the specimens were immersed in $150 \mathrm{~mL}$ beakers containing $1 \mathrm{M} \mathrm{HCl}$ solution with and without various concentrations of the inhibitors for 2 hours. At the end of the testing period, the specimens were taken out and rinsed thoroughly with 
distilled water and acetone, dried and weighed accurately again and the average value of three replicates reported.

\subsection{Electrochemical Measurements}

The electrochemical measurements were carried out by using CH1608D electrochemical workstation (manufactured by $\mathrm{CH}$ Instruments, Austin, USA). The cell consist of three electrodes namely, working electrode (steel), counter electrode (platinum) and reference electrode ( $\mathrm{Ag} / \mathrm{AgCl}$ electrode). First, the WE was immersed in the electrolyte solution for 30 minutes to establish a steady state open circuit potential (OCP). EIS measurements were then performed at OCP in a frequency range from $0.1 \mathrm{~Hz}$ to $100 \mathrm{KHz}$ with a signal amplitude perturbation of $5 \mathrm{mV}$ peak to peak. The polarization measurements were performed immediately after EIS measurements in the same corrosion cell containing the same electrode and test solution with a scan rate of $1 \mathrm{mVs}^{-1}$ commencing from -250 $\mathrm{mV}$ to $+250 \mathrm{mV}$ with respect to OCP. Corrosion current density values were obtained by extrapolation method.

\section{Results and Discussion}

1) The chemical structures of the inhibitor compounds were characterized by elemental, FTIR, ${ }^{1} \mathrm{H}$-NMR, ${ }^{13} \mathrm{C}-\mathrm{NMR}$ and single crystal X-ray diffraction studies.

MFHPZ (2): Yield: 80\%. Anal. Calcd.: C, 66.60; H, 4.80; N, 22.20\%. Found: C, 66.21; H, 4.67; N, 22.21\%. IR ( $\left.\mathrm{KBr}, \mathrm{cm}^{-1}\right): 3436,3235,1626,1583.7,1539.1$, 995.6, 939.7, 800. ${ }^{1} \mathrm{H}$ NMR ( $\left.\delta \mathrm{ppm}\right): 2.41$ (s, H6'), 6.11 (d, J = 6.9, 1H, H-2'), 6.66 (d, J = 6.9, 1H, H-3'), 7.62 (d, J = 7.3 Hz, 1H, H-6), 7.67 (d, J = 7.3 Hz, 1H, H-6, H-9), 7.48 - 7.50 (m, 2H, H-7,8), 7.82 (s, H5'), 8.27 (s, H4), 8.43, 10.60 (s, H2). ${ }^{13} \mathrm{CNMR}$ ( $\left.\delta \mathrm{ppm}\right)$ : 14.01 (C6'), 148.76 (C1'), 108.43, 115.28 (C2', C3'), 143.51 (C4'), 149.21 (C5'), 155.15 (C1), 138.03 (C4), 131.57 (C5), 126.74 (C6), 127.35 (C7), 131.97 (C8), 126.03 (C9), 124.16 (C10).

ACPHPZ (3): Yield $79 \%$. Anal. Calcd. for $\left(\mathrm{C}_{15} \mathrm{H}_{13} \mathrm{~N}_{5}\right)$ : C, 58.40; H, 5.60; N, 22.70. Found; C, 58.40; H, 5.40; N, 22.43\%. IR $\left(\mathrm{KBr}, \mathrm{cm}^{-1}\right): 3438.6,3317.1,3054$, 2922.1, 1605.6, 1591.5, 1569.1, 1532.6, 1468.1, 1432.8, 1385.6, 1353.6, 1250.1, 1146.8, 1022.9, 990.4, 953.3, 906.8, 780.5, 656.7. 1H-NMR (DMSO-d6) 8.78, 8.77 [d, $1 \mathrm{H}, \delta(\mathrm{Ar}-\mathrm{H})$ pyr $], 8.30-8.25[\mathrm{~m}, 2 \mathrm{H}, \delta(\mathrm{Ar}-\mathrm{H}) \mathrm{pyr}], 7.89-7.87[\mathrm{t}, 1 \mathrm{H}$, $\delta(\mathrm{Ar}-\mathrm{H}) \mathrm{pyr}$ ], $3.89[\mathrm{~s}, 4 \mathrm{H}, \delta(2 \mathrm{CH})], 3.85-3.83[\mathrm{t}, 2 \mathrm{H}, \delta(\mathrm{CH})], 2.91-2.90[\mathrm{t}, 6 \mathrm{H}$, $\delta(\mathrm{N}-\mathrm{CH})], 2.62[\mathrm{~s}, 3 \mathrm{H}, \delta(\mathrm{CH} 3)] .13 \mathrm{C}-\mathrm{NMR}(\mathrm{DMSO}-\mathrm{d} 6)[1 \mathrm{C}, \delta(\mathrm{C}=\mathrm{N})], 168.38$ $\delta(\mathrm{C}), 146.49 \delta(\mathrm{CH}), 140.65 \delta(\mathrm{CH}), 128.03 \delta(\mathrm{CH}), 124.05 \delta(\mathrm{CH})$ [5C, $\delta(\mathrm{Ar}-\mathrm{pyr})]$, $154.88[2 \mathrm{C}, \delta(2 \mathrm{CH})], 149.55[1 \mathrm{C}, \delta(\mathrm{CH})], 126.09[1 \mathrm{C}, \delta(\mathrm{CH})], 137.12[1 \mathrm{C}$, $\delta(\mathrm{CH})], 124[1 \mathrm{C}, \delta(\mathrm{CH})]$.

ACTHPZ(4): Yield: 70\%. Anal. Calcd.: C, 66.60; H, 4.80; N, 22.20\%. Found: C, 66.21; H, 4.67; N, 17.21; S, 5.2\%. IR (KBr, cm $\left.{ }^{-1}\right): 3436,3235,1626,1583.7,1539.1$, 995.6, 939.7, 800. ${ }^{1} \mathrm{H}$ NMR ( $\left.\delta \mathrm{ppm}\right): 1.98$ (s, H7'), 2.32 (s, H6'), 5.91 (d, J = 7.1 Hz, 1H, H-2'), 6.46 (d, J = 7.1 Hz, 1H, H-3'), 7.52 (d, J = 7.4 Hz, 1H, H-6), 7.58 (d, J = 7.4 Hz, 1H, H-9), 7.28 - 7.30 (m, 2H, H-7, 8), 8.22(s, H4), 8.43, 10.30 (s, 
H2). ${ }^{13} \mathrm{C}$ NMR ( $\left.\delta \mathrm{ppm}\right): 14.81,15.41$ (C6', C7'), $138.72\left(\mathrm{C1}^{\prime}\right), 113.23,120.21$ (C2', C3'), 133.71 (C4'), 153.20 (C5'), 155.19 (C1), 138.09 (C4), 131.57 (C5), 126.74 (C6), 127.35 (C7), 131.97 (C8), 126.03 (C9), 124.16 (C10).

On the basis of the elemental analysis, IR, NMR and X-ray diffraction techniques, the chemical structures and molecular weight of the inhibitory compounds listed in Table 1 were assigned.

2) Weight Loss measurements:

The corrosion rate in milligrams per square centimeter per hour $\left(\mathrm{mg} \cdot \mathrm{cm}^{-2} \cdot \mathrm{h}^{-1}\right)$ was evaluated using the formula

$$
\text { Corrosion rate, } C R=\frac{\Delta W}{A T}
$$

where: $\Delta W=$ Weight loss, $A=$ Total surface area of the specimen in $\mathrm{cm}^{2}, T=$ Total time the sample was immersed in hours, $C R=$ Corrosion rate in milligrams per centimeter squared per hour. The specimens used had rectangular geometry with each having a total surface area of $A=1 \times \mathrm{w}$, where: $l=$ length of the specimen in $\mathrm{cm}, w=$ width of the specimen in $\mathrm{cm}$. The percentage inhibitor

Table 1. Chemical names, structure and molecular weight of the three hydralazine 1 and its derivatives, 2,3 , and 4 .

Hydralazine
hydrochloride Notation $\begin{gathered}\text { Molecular Weight } \\ \left(\mathrm{g} \cdot \mathrm{mol}^{-1}\right)\end{gathered}$


efficiency (IE \%) was calculated from the equation:

$$
I E \%=\frac{C R_{1}-C R_{2}}{C R_{1}} \times 100
$$

where $C R_{1}$ and $C R_{2}$ are the corrosion rate of mild steel in the absence and presence of the Schiff base inhibitors, respectively. The values of weight-loss (mg), corrosion rate $\left(\mathrm{mg} \cdot \mathrm{cm}^{-2} \cdot \mathrm{hr}^{-1}\right)$ and the inhibition efficiency are presented in Table 2 while Figure 1 and Figure 2 represent the variation of dissolution rates and inhibition efficiencies (\%IE) for 3 and 4 as representative compounds.

Table 2. Corrosion parameters obtained from weight loss measurement of mild steel in 1 $\mathrm{M} \mathrm{HCl}$ containing different concentrations of inhibitors at $303 \mathrm{~K}$.

\begin{tabular}{|c|c|c|c|c|}
\hline Inhibitor & $\begin{array}{c}\text { Concentration } \\
\text { (M) }\end{array}$ & $\begin{array}{l}\text { Weight Loss } \\
(\mathrm{mg})\end{array}$ & $\begin{array}{l}\text { Corrosion rate } \\
\left(\mathrm{mg} \cdot \mathrm{cm}^{-2} \cdot \mathrm{hr}^{-1}\right)\end{array}$ & $\begin{array}{c}\text { Inhibition efficiency } \\
\text { (IE\%) }\end{array}$ \\
\hline- & 0 & 27.52 & 3.44 & - \\
\hline \multirow{4}{*}{ HPZ (1) } & $0.63 \times 10^{-4}$ & 16.00 & 2.0 & 42 \\
\hline & $1.25 \times 10^{-4}$ & 14.40 & 1.8 & 48 \\
\hline & $2.5 \times 10^{-4}$ & 12.80 & 1.6 & 53 \\
\hline & $5 \times 10^{-4}$ & 7.20 & 0.9 & 74 \\
\hline \multirow{4}{*}{ ACPHPZ (2) } & $0.63 \times 10^{-4}$ & 16.80 & 2.1 & 40 \\
\hline & $1.25 \times 10^{-4}$ & 11.20 & 1.4 & 59 \\
\hline & $2.5 \times 10^{-4}$ & 6.40 & 0.8 & 76 \\
\hline & $5 \times 10^{-4}$ & 2.40 & 0.3 & 91 \\
\hline \multirow{4}{*}{ ACTHPZ (3) } & $0.63 \times 10^{-4}$ & 10.40 & 1.3 & 62 \\
\hline & $1.25 \times 10^{-4}$ & 8.80 & 1.1 & 68 \\
\hline & $2.5 \times 10^{-4}$ & 5.60 & 0.7 & 80 \\
\hline & $5 \times 10^{-4}$ & 2.00 & 0.25 & 93 \\
\hline \multirow{4}{*}{ MFHPZ (4) } & $0.63 \times 10^{-4}$ & 18.40 & 2.3 & 33 \\
\hline & $1.25 \times 10^{-4}$ & 15.20 & 1.9 & 45 \\
\hline & $2.5 \times 10^{-4}$ & 12.80 & 1.6 & 53 \\
\hline & $5 \times 10^{-4}$ & 8.00 & 1.0 & 71 \\
\hline
\end{tabular}

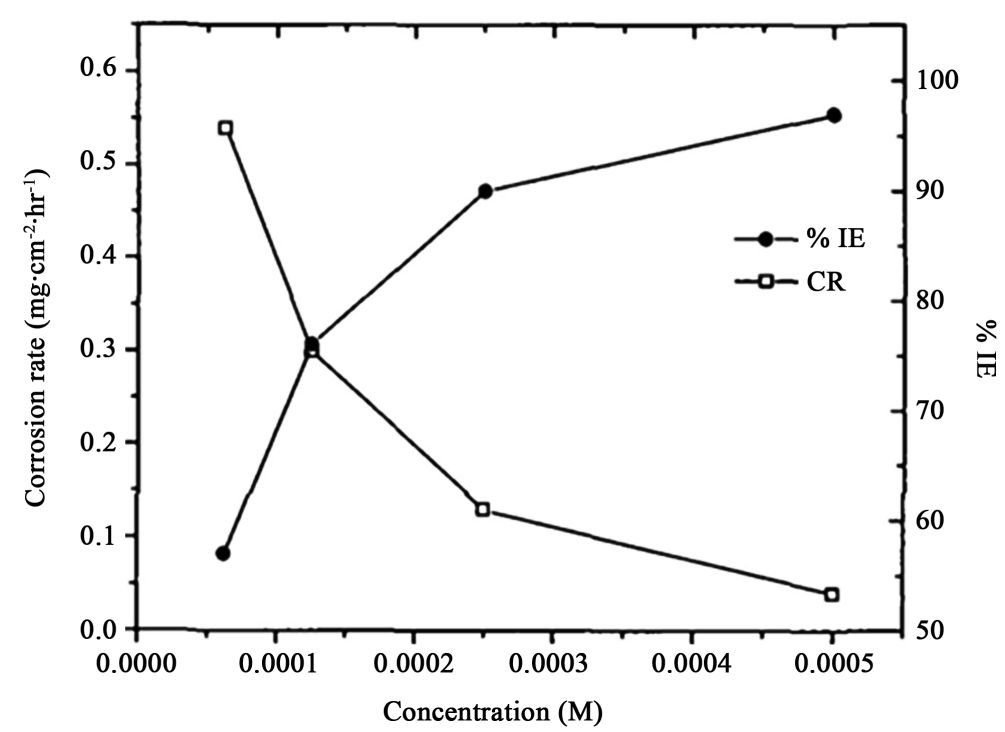

Figure 1. Variation of CR and \% I E with concentration of 3 obtained from weight loss method. 


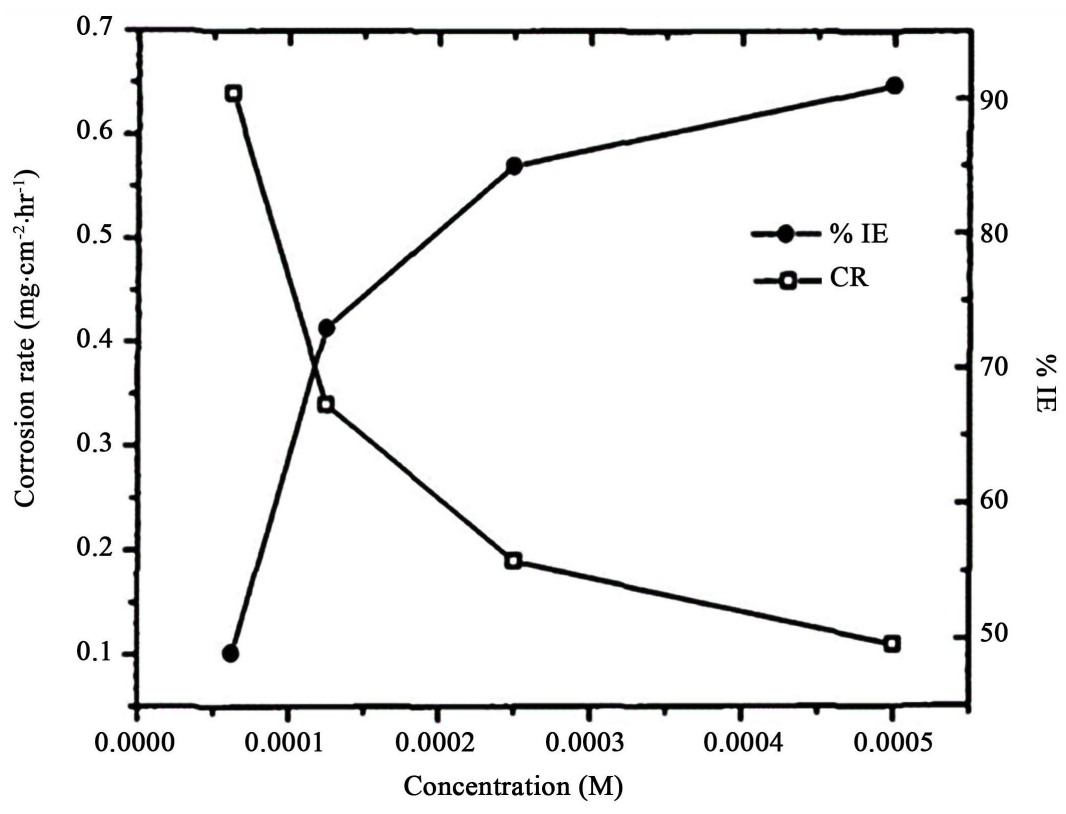

Figure 2. Variation of $\mathrm{CR}$ and \% I E with concentration of 4 obtained from weight loss method.

From Table 2 of weight loss measurements, it was observed that a significant decrease in dissolution rate occurred over the concentration range $0.63 \times 10^{-4}$ to $5 \times 10^{-4} \mathrm{M}$ and a corresponding increase in inhibition efficiencies (\%IE) of the inhibitors. The decreased in corrosion rate and the increase in inhibition efficiencies (\%IE) with the application of the inhibitors can be attributed to the interaction of the inhibitor molecules with the steel surface by adsorption process leading to the blocking of more active corrosion sites [21]. The maximum inhibition efficiency of $93 \%$ was observed in the presence of 3 at $5 \times 10^{-4} \mathrm{M}$ concentration. The weight loss measurements indicated that the inhibition efficiency of the compounds at the same concentration follows the order $4>3>1>2$.

\section{3) Polarization measurement}

Figures 3-6 show the anodic and cathodic polarization curves for mild steel in $1 \mathrm{M} \mathrm{HCl}$ in the absence and presence of different concentrations of the inhibitors $1,2,3$ and 4 at $303 \mathrm{~K}$.

As shown in the figures, the corrosion potential of mild steel in $1 \mathrm{M} \mathrm{HCl}$ acid is negative with increasing concentration of the inhibitors. In addition, the anodic as well as the cathodic polarization curves shifted towards lower current density values in the presence of the inhibitors. This indicated that, the inhibitors acted in such a manner that both the anodic and cathodic reactions were influenced by them simultaneously, almost to the same extent showing mixed nature of the inhibitors. The computed corrosion parameters from this method such as corrosion potential $\left(\mathrm{E}_{\text {corr }}\right)$, corrosion current density $\left(\mathrm{I}_{\text {corr }}\right)$, anodic Tafel slope $(\beta \mathrm{a})$, cathodic Tafel slope $(\beta c)$, degree of coverage $(\theta)$ and inhibition efficiency (IE\%) at the different concentrations of the inhibitors at $303 \mathrm{~K}$, are given in Table 3. The surface coverage $(\theta)$ was calculated using Equation (3) below [6]: 


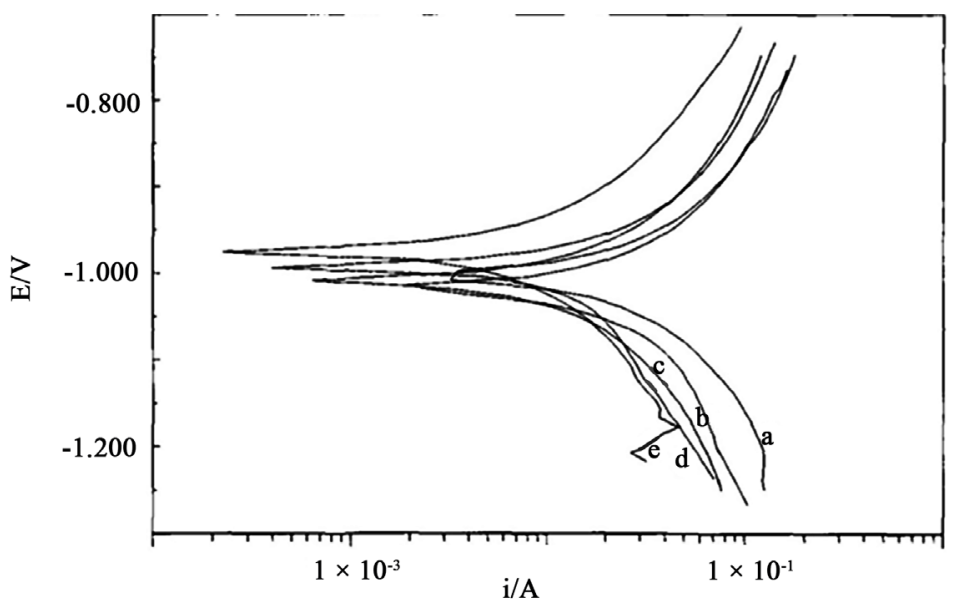

Figure 3. Polarization curves of mild steel in $1 \mathrm{M} \mathrm{HCl}$ in presence of different concentration of 3 at $303 \mathrm{~K}$. (a) $\mathrm{HCl}$ blank (b) $0.63 \times 10^{-4} \mathrm{M}$ (c) $1.25 \times 10^{-4} \mathrm{M}$ (d) $2.50 \times 10^{-4} \mathrm{M}$ (e) $5.0 \times 10^{-4} \mathrm{M}$.

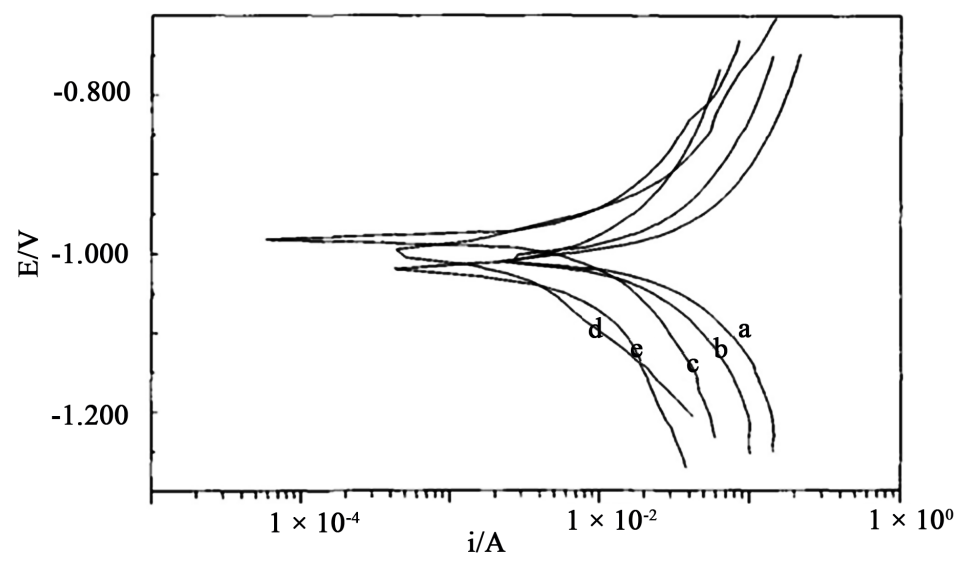

Figure 4. Polarization curves of mild steel in $1 \mathrm{M} \mathrm{HCl}$ in presence of different concentration of 4 at $303 \mathrm{~K}$. (a) $\mathrm{HCl}$ blank (b) $0.63 \times 10^{-4} \mathrm{M}$ (c) $1.25 \times 10^{-4} \mathrm{M}$ (d) $2.50 \times 10^{-4}$ (e) 5.0 $\times 10^{-4} \mathrm{M}$.

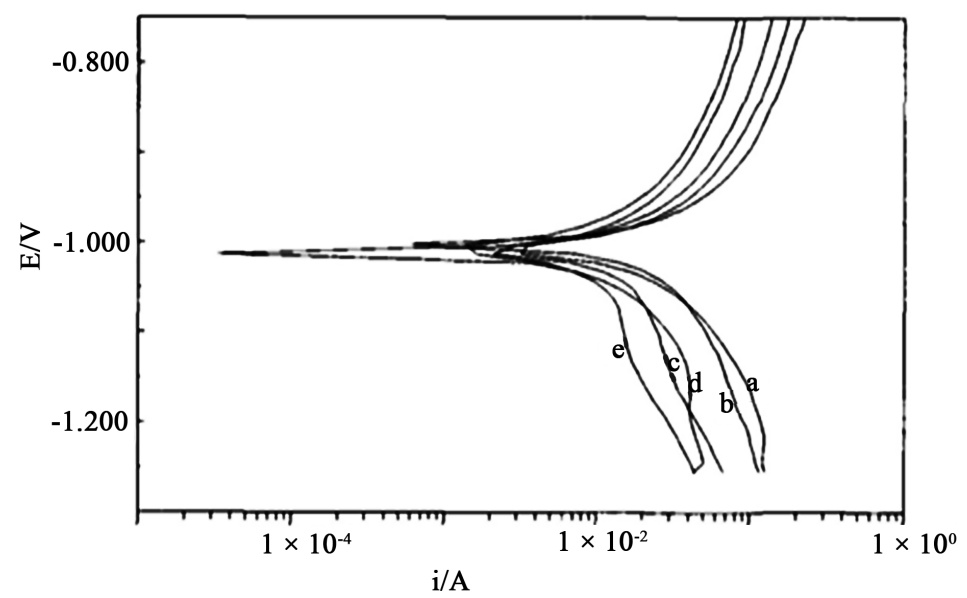

Figure 5. Polarization curves of mild steel in $1 \mathrm{M} \mathrm{HCl}$ in presence of different concentration of 1 at $303 \mathrm{~K}$. (a) $\mathrm{HCl}$ blank (b) $0.63 \times 10^{-4} \mathrm{M}$ (c) $1.25 \times 10^{-4} \mathrm{M}$ (d) $2.50 \times 10^{-4} \mathrm{M}$ (e) $5.0 \times 10^{-4} \mathrm{M}$. 


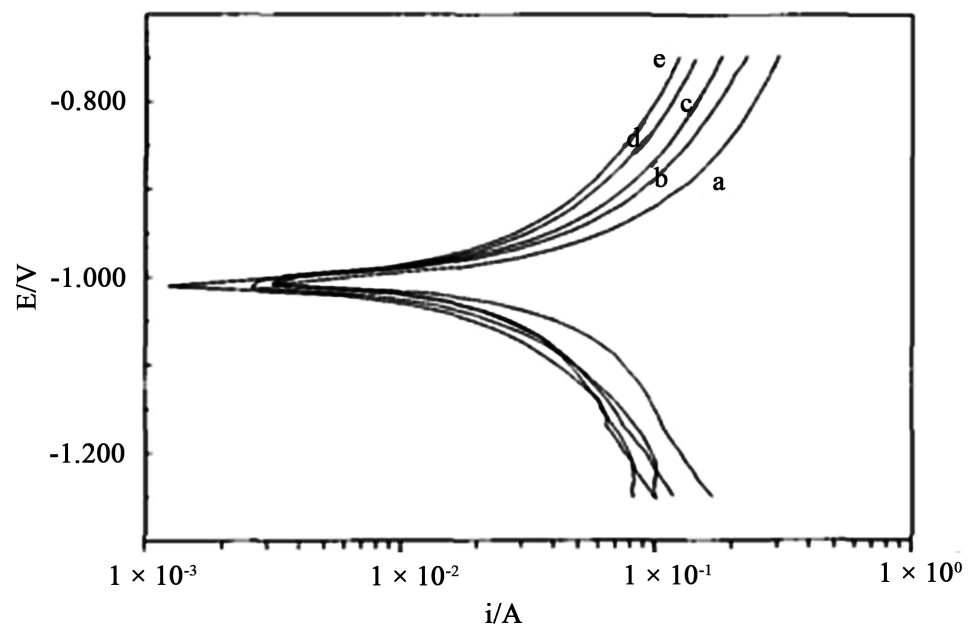

Figure 6. Polarization curves of mild steel in $1 \mathrm{M} \mathrm{HCl}$ in presence of different concentration of 2 at $303 \mathrm{~K}$. (a) HCl blank (b) $0.63 \times 10^{-4} \mathrm{M}$ (c) $1.25 \times 10^{-4} \mathrm{M}$ (d) $2.50 \times 10^{-4} \mathrm{M}$ (e) $5.0 \times 10^{-4} \mathrm{M}$.

Table 3. Corrosion parameters obtained from polarization measurements for steel in $1 \mathrm{M}$ $\mathrm{HCl}$ containing various concentrations of inhibitors at $303 \mathrm{~K}$.

\begin{tabular}{|c|c|c|c|c|c|c|c|}
\hline Inhibitor & $\begin{array}{c}\text { Concentration } \\
\text { (M) }\end{array}$ & $\begin{array}{l}-E_{\text {corr }} \\
(\mathrm{mV})\end{array}$ & $\begin{array}{c}\mathrm{I}_{\text {corr }} \\
\left(\mathrm{mAcm}^{-2}\right)\end{array}$ & $\theta$ & $\begin{array}{c}\beta_{\mathrm{a}} \\
(\mathrm{mV} / \mathrm{dec})\end{array}$ & $\begin{array}{c}\beta_{\mathrm{c}} \\
(\mathrm{mV} / \mathrm{dec})\end{array}$ & (IE\%) \\
\hline \multirow{5}{*}{$\mathrm{HPZ}(1)$} & - & 1.007 & 0.0215 & - & 0.276 & 0.245 & - \\
\hline & $0.63 \times 10^{-4}$ & 0.976 & 0.0132 & 0.39 & 0.179 & 0.163 & 39 \\
\hline & $1.25 \times 10^{-4}$ & 0.992 & 0.0121 & 0.44 & 0.218 & 0.159 & 44 \\
\hline & $2.5 \times 10^{-4}$ & 1.011 & 0.0104 & 0.52 & 0.178 & 0.168 & 52 \\
\hline & $5 \times 10^{-4}$ & 1.061 & 0.0063 & 0.71 & 0.193 & 0.175 & 71 \\
\hline \multirow{4}{*}{ MFHPZ(2) } & $0.63 \times 10^{-4}$ & 1.008 & 0.0149 & 0.31 & 0.234 & 0.225 & 31 \\
\hline & $1.25 \times 10^{-4}$ & 0.997 & 0.0119 & 0.45 & 0.195 & 0.258 & 45 \\
\hline & $2.5 \times 10^{-4}$ & 0.985 & 0.0091 & 0.58 & 0.224 & 0.248 & 58 \\
\hline & $5 \times 10^{-4}$ & 0.985 & 0.0065 & 0.71 & 0.261 & 0.203 & 71 \\
\hline \multirow{4}{*}{ ACPHPZ(3) } & $0.63 \times 10^{-4}$ & 0.976 & 0.0142 & 0.34 & 0.302 & 0.232 & 34 \\
\hline & $1.25 \times 10^{-4}$ & 0.992 & 0.0103 & 0.52 & 0.266 & 0.239 & 52 \\
\hline & $2.5 \times 10^{-4}$ & 1.011 & 0.0058 & 0.73 & 0.278 & 0.258 & 73 \\
\hline & $5 \times 10^{-4}$ & 1.061 & 0.0028 & 0.87 & 0.288 & 0.261 & 87 \\
\hline \multirow{4}{*}{ ACTHPZ(4) } & $0.63 \times 10^{-4}$ & 1.009 & 0.0088 & 0.59 & 0.182 & 0.196 & 59 \\
\hline & $1.25 \times 10^{-4}$ & 1.005 & 0.0077 & 0.64 & 0.178 & 0.183 & 64 \\
\hline & $2.5 \times 10^{-4}$ & 1.018 & 0.0047 & 0.78 & 0.175 & 0.193 & 78 \\
\hline & $5 \times 10^{-4}$ & 0.983 & 0.0017 & 0.92 & 0.173 & 0.202 & 92 \\
\hline
\end{tabular}

where $\mathrm{I}_{\text {corr(uninh) }}$ and $\mathrm{I}_{\text {corr(inh) }}$ are the corrosion current densities in the absence and presence of the inhibitors respectively. The inhibition efficiency (IE \%) was computed as:

$$
\mathrm{IE} \%=\theta \times 100
$$

In each of the cases, the displacement of the cathodic Tafel slope $(\beta a)$ and the 
anodic Tafel slope $(\beta c)$ were not changed markly which clearly show that the inhibitors acted by adsorption process, without changing the mechanism of the reaction [22]. Also, the results showed that in all cases, Tafel lines shifted towards higher potentials in both anodic and cathodic directions as the concentration of the inhibitors increased. Thus the inhibitors influenced both anodic and cathodic reactions during the corrosion inhibition process [10]. That is, the anodic Tafel slope $(\beta a)$ and cathodic Tafel slope $(\beta c)$ of the inhibitors were found to change with inhibitor concentrations, indicating that the inhibitors affected both of these reactions.

Furthermore, the results revealed that inhibition efficiency increased with increased in concentration of the inhibitors. The maximum inhibition efficiency of $92 \%$ was observed in the presence of 4 at $5 \times 10^{-4} \mathrm{M}$. The IE\% was in the order $4>2>1 \approx 3$.

Due to these interesting results, the corrosion parameters obtained by this method were investigated at different temperatures in $1 \mathrm{M} \mathrm{HCl}$ containing $5 \times$ $10^{-4} \mathrm{M}$ concentration of the inhibitors (Table 4).

The result reveals that with increase in temperature there is correspondent increase $\mathrm{I}_{\text {corr }}$. But the inhibition efficiency decreases across the temperature range. Such behavior can be attributed to the adsorption of the inhibitor on the metal surface, and an increase in temperature results in desorption of some adsorbed inhibitor molecules, leading to a decrease in the inhibition efficiency as previously reported [23]. In acidic solutions, the anodic reaction of corrosion is the passage of metal ions from the metal surface into the solution, and the cathodic reaction is the discharge of hydrogen ions, which produces hydrogen gas or reduces oxygen. In this study, the values of corrosion potential $\left(\mathrm{E}_{\text {corr }}\right)$ and corrosion current density $\left(\mathrm{I}_{\text {corr }}\right)$ showed that the free corrosion potential $\left(\mathrm{E}_{\text {corr }}\right)$ was not affected in the presence of the inhibitors but the corrosion current density $\left(\mathrm{I}_{\text {corr }}\right)$ decreases with concentration (Table 3). The data obtained from weight loss and polarization studies were in good agreement with each other. In both methods the same order of inhibition efficiency (\%IE) was observed. The inhibition of corrosion was due to the blockage of the cathodic and anodic sites of the corroding surface.

Table 4. Corrosion parameters obtained from polarization measurements at different temperatures in $1 \mathrm{M} \mathrm{HCl}$ containing $5 \times 10^{-4} \mathrm{M}$ of inhibitors (Corr. Current $=\mathrm{A} \mathrm{cm}^{-2}$ ).

\begin{tabular}{|c|c|c|c|c|c|c|c|c|c|}
\hline \multirow{2}{*}{$\begin{array}{c}\text { Temp. } \\
(\mathrm{K})\end{array}$} & \multirow{2}{*}{$\begin{array}{c}1 \mathrm{M} \mathrm{HCl} \\
\text { Corr. } \\
\text { current }\end{array}$} & \multicolumn{2}{|c|}{$\mathrm{HPZ}(\mathbf{1})$} & \multicolumn{2}{|c|}{ MFHPZ(2) } & \multicolumn{2}{|c|}{ ACPHPZ(3) } & \multicolumn{2}{|c|}{ ACTHPZ(4) } \\
\hline & & $\begin{array}{l}\text { Corr. } \\
\text { current }\end{array}$ & $\% \mathrm{IE}$ & $\begin{array}{l}\text { Corr. } \\
\text { current }\end{array}$ & $\% \mathrm{IE}$ & $\begin{array}{l}\text { Corr. } \\
\text { current }\end{array}$ & $\% \mathrm{IE}$ & $\begin{array}{l}\text { Corr. } \\
\text { current }\end{array}$ & $\% \mathrm{IE}$ \\
\hline 303 & 0.0215 & 0.0063 & 71 & 0.0063 & 71 & 0.0028 & 87 & 0.0017 & 92 \\
\hline 313 & 0.0224 & 0.0074 & 67 & 0.0072 & 68 & 0.0034 & 85 & 0.0025 & 89 \\
\hline 323 & 0.0272 & 0.0103 & 62 & 0.0109 & 60 & 0.0054 & 80 & 0.0046 & 83 \\
\hline 333 & 0.0309 & 0.0136 & 56 & 0.0142 & 54 & 0.0074 & 76 & 0.0068 & 78 \\
\hline $\mathrm{E}_{\mathrm{a}}(\mathrm{KJ})$ & 11.5 & 21.9 & & 24.5 & & 28 & & 39. & \\
\hline
\end{tabular}




\section{4) Electrochemical impedance spectroscopy measurements}

Impedance measurements of steel immersed in $1 \mathrm{M} \mathrm{HCl}$ solutions without and with 4 and 3 as representative inhibitor at OCP are presented in the form Nyquist plots in Figure 7 and Figure 8 respectively.

It was observed that as the concentration of the are inhibitors increases the diameter of capacitance loop and consequently the values of charge transfer resistance $\left(R_{p}\right)$ increases, which was an indication of the inhibiting action. The diameter of the semi-circle increases in the order of $4>3$. The impedance diagrams obtained are not perfect semicircles; this is because of the typical behavior of solid metal electrode that shows frequency dispersion of the impedance data [24] [25] which is attributed to the roughness and other inhomogeneities of the solid surface [26].

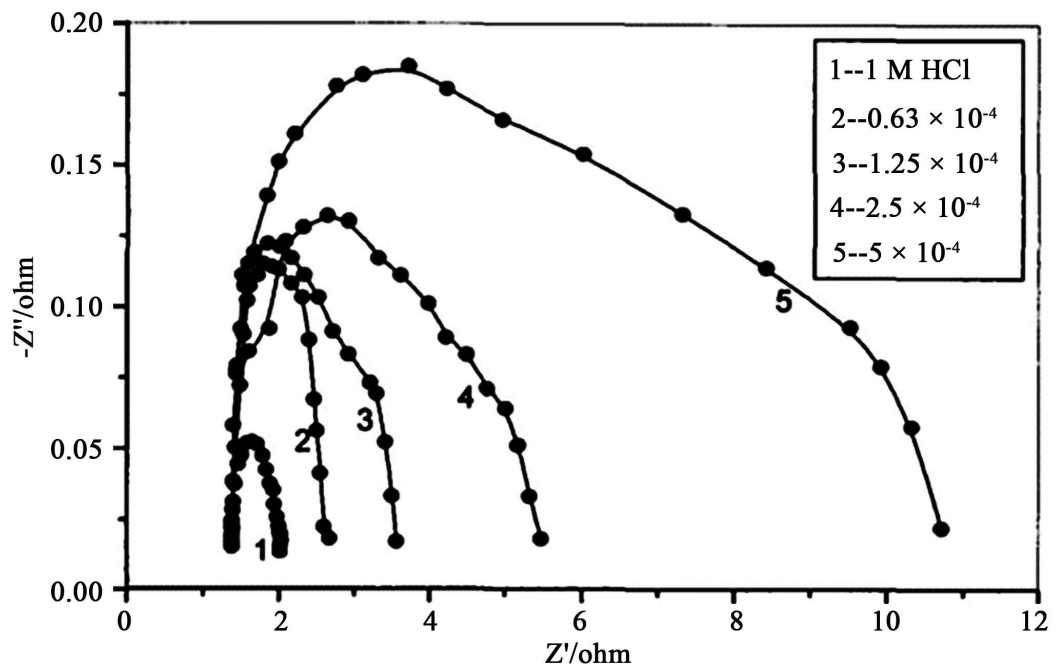

Figure 7. Nyquist plot for steel in $1 \mathrm{M} \mathrm{HCl}$ in the presence of different concentration of 4 .

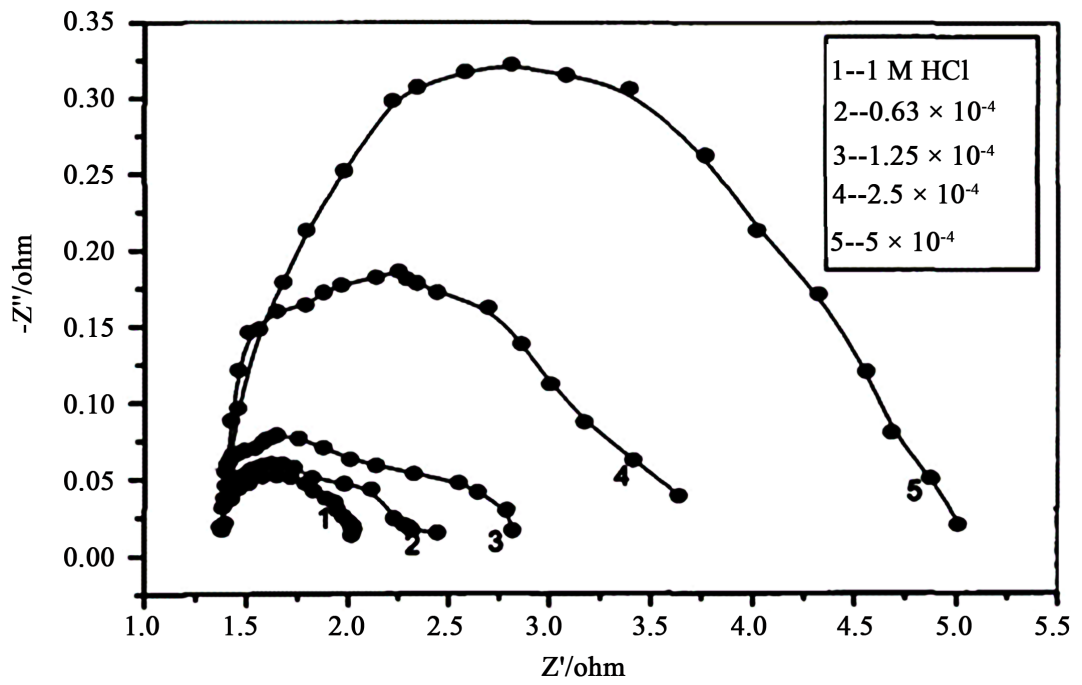

Figure 8. Nyquist plot for steel in $1 \mathrm{M} \mathrm{HCl}$ in the presence of different concentration of 3. 
Similarly, the EIS experiments also confirmed the results of the weight loss and polarization experiments. The equivalent circuit model shown in Figure 9 below was used to fit the EIS test parameters. As shown in the figure, $R_{s}$ is the solution resistance; $\mathrm{R}_{\mathrm{ct}}$ is the charge transfer resistance calculated by from the difference in impedance at lower and higher frequencies; $\mathrm{CPE}_{\mathrm{dl}}$ is the constant phase element of the double layer is used to replace capacitance; $R_{a d}$ is the adsorbed layer resistance and $\mathrm{CPE}_{\mathrm{ad}}$ is the constant phase element of the adsorbed layer.

The constant phase element (CPE) is introduced in the circuit instead of a pure double layer capacitor to give a more accurate fit. The impedance values of $\mathrm{CPE}$ for the steel electrode in $1 \mathrm{M} \mathrm{HCl}$ solution are expressed as [27]:

$$
Z_{C P E}=\frac{1}{\Upsilon_{o}(j \omega)^{n}}
$$

where $\Upsilon_{o}$ represents the magnitude of the $\mathrm{CPE}, \omega$ represents the angular frequency $(\omega=2 \pi \mathrm{f}), \mathrm{n}$ is the deviation parameter of the CPE: $-1 \leq n \leq 1$, and $j$ is an imaginary number. The values of the interfacial capacitance (the capacitance of the electric double layer) $\left(C_{d l}\right)$ can be calculated from the CPE parameter values $\Upsilon_{o}$ and $n$ using Equation (6) [28]

$$
C_{d l}=\Upsilon_{o}\left(j \omega_{\max }\right)^{n-1}
$$

The inhibition efficiencies (IE \%) were calculated from the charge transfer resistance using the Equation (7) below:

$$
I E \%=\frac{R_{c t}^{\prime}-R_{c t}}{R_{c t}^{\prime}} \times 100
$$

where $R_{c t}^{\prime}$ and $R_{c t}$ indicate the values of the charge transfer resistances in the presence and absence of the indicators respectively.

Values of EIS parameters corresponding to the impedance spectra recorded in the presence of the investigated compounds are listed in Table 5.

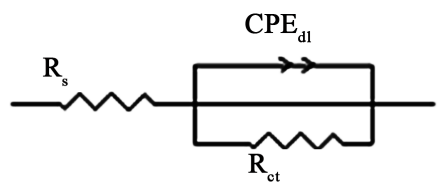

(a)

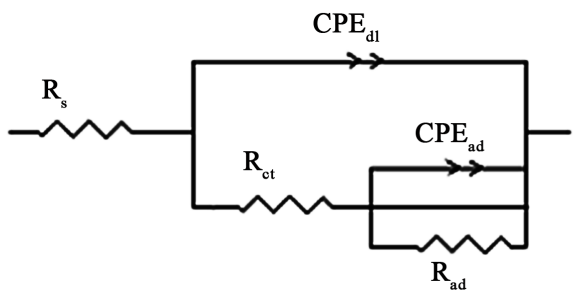

(b)

Figure 9. The equivalent circuit model used to fit the impedance data for mild steel in the (a) absence; and (b) presence of inhibitors. 
Table 5. Electrochemical impedance parameters of steel in $1 \mathrm{M} \mathrm{HCl}$ in the presence and absence of the representative inhibitors at different concentrations at $303 \mathrm{~K}$.

\begin{tabular}{ccccccc}
\hline Inhibitor & Concentration $(\mathrm{M})$ & $R_{s}(\mathrm{ohm})$ & $R_{c t}(\mathrm{Ohm})$ & $\mathrm{CPE}(\mathrm{F})$ & $\mathrm{n}$ & $\% \mathrm{IE}$ \\
\hline- & 0 & 1.45 & 0.654 & $2.86 \times 10^{-2}$ & 0.863 & - \\
& & & & & & \\
& $0.63 \times 10^{-4}$ & 1.57 & 1.07 & $1.71 \times 10^{-2}$ & 0.544 & 39 \\
ACPHPZ (3) & $1.25 \times 10^{-4}$ & 1.72 & 1.45 & $1.32 \times 10^{-2}$ & 0.535 & 55 \\
& $2.5 \times 10^{-4}$ & 1.91 & 2.26 & $7.63 \times 10^{-3}$ & 0.511 & 71 \\
& $5 \times 10^{-4}$ & 1.88 & 3.63 & $4.87 \times 10^{-3}$ & 0.618 & 82 \\
& & & & & & \\
ACTHPZ (4) & $0.63 \times 10^{-4}$ & 1.8 & 1.29 & $1.49 \times 10^{-2}$ & 0.87 & 49 \\
& $1.25 \times 10^{-4}$ & 1.89 & 2.18 & $8.42 \times 10^{-3}$ & 0.838 & 70 \\
& $2.5 \times 10^{-4}$ & 2.01 & 4.09 & $5.42 \times 10^{-3}$ & 0.949 & 84 \\
& $5 \times 10^{-4}$ & 1.86 & 9.34 & $3.05 \times 10^{-3}$ & 0.974 & 93 \\
\hline
\end{tabular}

In EIS, value of $R_{c t}$ reflects the degree of difficulty in corrosion, the higher the value is, the lower the corrosion rate [29]. It can be seen from the table that for both inhibitor compounds, the values of $R_{c t}$ increases significantly with increasing concentrations of the inhibitors, which demonstrates that the inhibitors prevent the corrosion reaction effectively. The results also showed that the IE\% increased with an increase in the concentration of the inhibitors. This result is in good agreement with those obtained from weight-loss and potentiodynamic polarization measurement.

It was also observed from Table 5 that for both compounds, the values of electrolyte resistance $\left(R_{s}\right)$ obtained in the pure medium increased in the presence of the investigated compounds. This has been attributed to the change in the conductivity of the solution. The table shows that the charge transfer resistance $\left(R_{c t}\right)$ increased with an increase in the inhibitor concentrations. Large transfer resistances are associated with systems that corrode slowly [30]. Besides the increase in the value of $R_{c p}$ the value of CPE obtained in the blank solution is drastically decreased in the presence of the inhibitors. This was co-related to the decrease in the area on steel surface exposed to the corrosive solution (increase in the area covered with the inhibitors) as a result of adsorption [10]. The decrease in $\mathrm{CPE} / \mathrm{C}_{\mathrm{dl}}$ values which could result from a decrease in local dielectric constant and/or an increase in the thickness of the electric double layer, suggest that the inhibitors function by adsorption at the metal/solution interface.

Based on $\theta$ values obtained from polarization measurements, the adsorption mechanism of the inhibitors on the mild steel in $1 \mathrm{M} \mathrm{HCl}$ can be described by Langmuir adsorption model [31] for $\mathbf{3}$ and $\mathbf{2}$ inhibitor compounds as follows: while, the adsorption mechanism of the 4 and 1 inhibitor compounds on the mild steel in $1 \mathrm{M} \mathrm{HCl}$ can be described by the Temkin adsorption Model [10].

Thermodynamic parameters are important in understanding of the inhibition mechanism. Table 6 depicts the thermodynamic functions for the dissolution of the mild steel without and with optimum concentrations of the inhibitors at various temperatures which were calculated. The negative values $\Delta \mathrm{H}$ and $\Delta \mathrm{G}$ and the positive value of $\Delta S$ may be attributed to spontaneous adsorption of the 
Table 6. Thermodynamic parameters for the adsorption of inhibitors on mild steel in 1 $\mathrm{M} \mathrm{HCl}$.

\begin{tabular}{|c|c|c|c|c|c|}
\hline Inhibitor & Temp (K) & $-\Delta \mathrm{H}\left(\mathrm{KJ} \cdot \mathrm{mol}^{-1}\right)$ & $10^{-4} \mathrm{~K}$ & $-\Delta \mathrm{G}\left(\mathrm{KJ} \cdot \mathrm{mol}^{-1}\right)$ & $\Delta \mathrm{S}\left(\mathrm{KJ} \cdot \mathrm{mol}^{-1}\right)$ \\
\hline \multirow{4}{*}{ HPZ (1) } & 303 & \multirow{4}{*}{19.9} & 4.9 & 37.3 & - \\
\hline & 313 & & 4.1 & 38.1 & 80 \\
\hline & 323 & & 3.3 & 38.8 & 75 \\
\hline & 333 & & 2.5 & 39.2 & 63 \\
\hline \multirow{4}{*}{ MFHPZ (2) } & 303 & \multirow{4}{*}{26.3} & 4.9 & 37.3 & - \\
\hline & 313 & & 4.3 & 38.2 & 90 \\
\hline & 323 & & 3.0 & 38.5 & 60 \\
\hline & 333 & & 1.9 & 38.4 & 37 \\
\hline \multirow{4}{*}{ ACPHPZ (3) } & 303 & \multirow{4}{*}{22.1} & 13.4 & 39.9 & - \\
\hline & 313 & & 11.3 & 40.7 & 80 \\
\hline & 323 & & 8.0 & 41.1 & 60 \\
\hline & 333 & & 6.3 & 41.7 & 60 \\
\hline \multirow{4}{*}{ ACTHPZ (4) } & 303 & \multirow{4}{*}{33.2} & 23 & 41.2 & - \\
\hline & 313 & & 16.2 & 41.7 & 50 \\
\hline & 323 & & 9.8 & 41.7 & 25 \\
\hline & 333 & & 7.1 & 42.1 & 30 \\
\hline
\end{tabular}

additives on the surface of the mild steel. Generally, it is well known that values of $\Delta \mathrm{G}_{\text {ads }}$ are of the order $-20 \mathrm{KJ} \cdot \mathrm{mol}^{-1}$ or lower indicating the electrostatic interaction between the charged molecules and charged metal (physical adsorption); those of order $-40 \mathrm{KJ} \cdot \mathrm{mol}^{-1}$ or higher involve haring or transfer of electrons from inhibitor molecules to form a coordinate type of bond (chemisorption) [32]. The results in Table 6 have values of $\Delta \mathrm{G}$ closer to $-40 \mathrm{KJ} \cdot \mathrm{mol}^{-1}$ indicating that the adsorption mechanism of the inhibitor compounds on the mild steel was typical of chemisorption.

The values of Ea for the inhibited and uninhibited corrosion reaction of mild steel have been calculated using Figure 10 and recorded in Table 4. The values of Ea found for inhibited systems were higher than for uninhibited system showing that the dissolution reaction of iron decreased in the presence of the inhibitors. It was found for the $\mathrm{HCl}$ solution that $\mathrm{Ea}$ is $11.5 \mathrm{KJ} \cdot \mathrm{mol}^{-1}$ while in the presence of $5 \times 10^{-4} \mathrm{M}$ concentration of inhibitors, the activation energies up to $39.8 \mathrm{KJ} \cdot \mathrm{mol}^{-1}$ revealing the retardation of the corrosion reaction. The marked changes in Ea suggest that the inhibitors may either participate in the electrode reactions or may change the potential difference of the metal-solution interface by adsorption [33]. The presence of these additives induce energy barrier for the corrosion reaction and this barrier increases with increasing additive concentration.

\section{Conclusions}

In this study, novel Schiff bases derived from hydralazine hydrochloride 1 viz, 3, 2 and $\mathbf{4}$ were successively synthesized and characterized using various spectroscopic methods. Weight loss, potentiodynamic and electrochemical impedance spectroscopy (EIS) measurements were used to study the inhibitory effect of the 


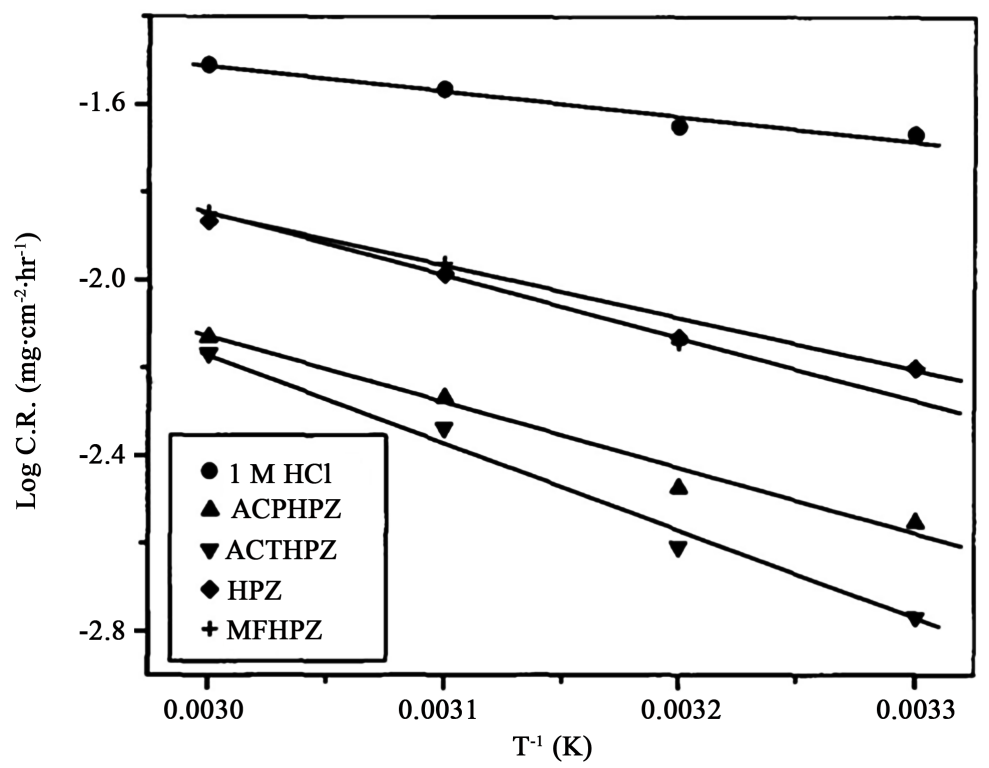

Figure 10. Arrhenius plot of corrosion rates with temperature in the presence and absence of inhibitors.

Schiff bases on the corrosion of mild steel in $1 \mathrm{M} \mathrm{HCl}$ solution. The compounds exhibited excellent inhibition performance as mixed-typed inhibitors.

The adsorption of the inhibitors follows Langmuir adsorption isotherm for $\mathbf{3}$ and 2 but Temkin adsorption isotherm for 4 and 1. Evaluation of the activation energy shows mixed adsorption with predominant chemisorption on the metal surface. For the representative inhibitor compounds 4 and 3, the EIS results revealed an increase in charge transfer resistance and a decrease in $\mathrm{CPE} / \mathrm{C}_{\mathrm{dl}}$ values when the inhibitors are added, hence an increase in inhibition efficiency (\%IE). This attributed to the increase in the thickness of the electrical double layer.

In general, the acidic corrosion of mild steel was reduced upon the addition of appropriate concentrations of the inhibitors. The inhibition efficiencies obtained from the chemical (weight loss) and electrochemical measurements were in good agreement. The inhibition efficiencies follow the order: $4>3>1>2$.

\section{Acknowledgements}

Partial support of this work by DAAD Academic Exchange fellowship is gratefully acknowledged.

\section{References}

[1] Shukla, S.K. Singh, A.K. and Quraishi, M.A. (2012) Triazines: Efficiency Corrosion Inhibitors for Mild Steel in Hydrochloric Acid. International Journal of Electrochemistry, 7, 3371-3389.

[2] Kumari, P.P., Shetty, P. and Rao, S.A. (2014) Electrochemical Measurements for the Corrosion Inhibition of Mild Steel in $1 \mathrm{M}$ Hydrochloric Acid by Using an Aromatic Hydrazide Derivative. Arabian Journal of Chemistry, 10, 653-663.

[3] Ranni, B.E.A. and Bassu, B.B.J. (2012) Green Inhibitors for Corrosion Protection of 
Metals and Alloys: An Overview. International Journal of corrosion, 2012, 1-15. https://doi.org/10.1155/2012/380217

[4] Ali, S.A., Saed, M.T. and Rahman, S.U. (2003) The Isoxazolidines: A New Class of Corrosion Inhibitors of Mild Steel in Acidic Medium. Corrosion Science, 45, 253-266. https://doi.org/10.1016/S0010-938X(02)00099-9

[5] Stupnisek-Lisac, E., Podbrsek, S. and Sorie, T. (1994) Non-Toxic Organic Zinc Inhibitors in Hydrochloric Acid. Journal of Applied Electrochemistry, 24, 779-784. https://doi.org/10.1007/BF00578094

[6] Ahmed, A.A., Abdul, A.H.K., Abu, B.M. and Sutiana, J. (2013) A Novel Hydrazinecarbothiamide as Potential Corrosion Inhibitor for Mild Steel in HCl. Materials, 6, 1420-1431. https://doi.org/10.3390/ma6041420

[7] Sankarap, S., Apavinasam, S., Pushpanaden, F. and Ahmed, M. (1991) Piperidine, Piperidones and Tetrahydrothiopyrones as Inhibitors for the Corrosion of Copper in $\mathrm{H}_{2} \mathrm{SO}_{4}$. Corrosion Science, 32, 193-203. https://doi.org/10.1016/0010-938X(91)90043-O

[8] Wang, L. (2001) Evaluation of 2-Mercaptobenzimidazole as Corrosion Inhibitor for Mild Steel in Phosphoric Acid. Corrosion Science, 43, 1637-1644. https://doi.org/10.1016/S0010-938X(01)00036-1

[9] Eldesoloky, A.M., Diab, M.A., El-Bindary, A.A., El-Sonbati, A.Z. and Seyam, H.A. (2015) Some Antipyrine Derivatives as Corrosion Inhibitors for Copper in Acidic Medium: Experimental and Quantum Chemical Molecular Dynamics Approach. Journal of Materials and Environmental Science, 6, 2148-2165.

[10] Obot, I.B. and Obi-Egbedi, N.O. (2010) Adsorption Properties and Inhibition of Mild Steel Corrosion in Sulphuric Acid Solution by Ketoconazole: Experimental and Theoretical Investigation. Corrosion Science, 52, 198-204. https://doi.org/10.1016/j.corsci.2009.09.002

[11] Hebbar, N., Praveen, B.M., Prasanna, B.M. and Venkatesha, T.V. (2014) Inhibition Effect of an Anti-HIV Drug on the Corrosion of Zinc in Acidic Medium. Procedia Materials Science, 5, 712-718.

[12] Pavithra, M.K., Venkatesha, T.V., Vathsala, K. and Nayana, K.O. (2013) Inhibiting Effects of Rabeprazole Sulfide on the Corrosion of Mild Steel in Acidic Chloride Solution. International Journal of Corrosion, 1-9.

[13] Kumar, S.H. and Karthikeyan, S. (2013) Torsemide and Furosemide as Green Inhibitors for the Corrosion of Mild Steel in the Hydrochloric Acid Medium. Industrial \& Engineering Chemistry Research, 52, 7457-7469. https://doi.org/10.1021/ie400815w

[14] Praveen, B.M. and Venkatesha, T.V. (2009) Metol as Corrosion Inhibitor for Steel. International Journal of Electrochemical Science, 4, 267-275.

[15] Akpan, I.A. and Offiong, N.A.O. (2013) Inhibition of Mild Steel Corrosion in Hydrochloric Acid Solution by Ciprofloxacin Drug. International Journal of Corrosion, 2013, 1-5. https://doi.org/10.1155/2013/301689

[16] Obot, I.B., Ebenso, E.E. and Kabanda, M.M. (2013) Metronidazole as an Environmentally Safe Corrosion Inhibitor for Mild Steel in $0.5 \mathrm{M} \mathrm{HCl}$ : Experimental and Theoretical Investigation. The Journal of Environmental Chemical Engineering, 1, 431-439. https://doi.org/10.1016/j.jece.2013.06.007

[17] Nfor, E.N., Husian, A., Majoumo-Mbe, F., Njah, I.N., Offiong, O.E. and Bourne, S.A. (2013) Synthesis, Crystal Structure and Antifungal Activity of Ni(II) Complex of a New Hydrazone Derived from Anti-Hypertensive Drug Hydralazine Hydroch- 
loride. Polyhedron, 63, 207-213. https://doi.org/10.1016/j.poly.2013.07.028

[18] Majoumo-Mbe, F., Nfor, E.N., Sengeh, E., Njong, R.N. and Offiong, O.E. (2015) Synthesis, Crystal and Biological Activity of 1-(Phthalazin-1(2H)-One)[(Pyridine-2-Yl)Ethylidene]Hydrazone and Its Cobalt (III) Complex. Communications in Inorganic Synthesis, 3, 40-46.

[19] Yong, J.N., Asobo, P.F., Nyongbela, K.D., Njong, R.N. and Nfor, O.N. (2016) Synthesis, Spectroscopic Studies and Antimicrobial Activity of Novel Aromatic Hydrazones Derived from Hydralazine-Phthalazine. American Chemical Science Journal, 14, 1-10. https://doi.org/10.9734/ACSJ/2016/26059

[20] Durowaye, S.I., Durowaye, V.O. and Begusa, B.M. (2014) Corrosion Inhibition of Mild Steel in Acid Medium by Methyl Red(2,4-Dimethylamino-2'-Carboxylazobenzene). International Journal of Engineering and Future Technology, 4, 1-5.

[21] Prasanna, B.M., Praveen, B.M., Hebbar, N. and Venkatarangaiah, T.V. (2014) Anticorrosion Potential of Hydralazine on Mild Steel in 1 M Hydrochloric Acid Solution. The Journal of Fundamental and Applied Sciences, 7, 222-243. https://doi.org/10.4314/jfas.v7i2.6

[22] Wang, Z. (2012) The Inhibition Effect of Bis-Benzimidazole Compound for Mild Steel in $0.5 \mathrm{M} \mathrm{HCl}$ Solution. International Journal of Electrochemical Science, 7, 1149-11160.

[23] Bentiss, F., Lebrini, M., Vezin, H., Chai, F., Traisnel, M. and Lagrenee, M. (2009) Enhanced Corrosion Resistance of Mild Steel in Normal Sulphuric Acid Medium by Some Macrocyclic Polyether Compounds Containing a 1,3,4-Thiadiazole Moiety: A SC Impedance and Computational Studies. Corrosion Science, 51, 2165-2173. https://doi.org/10.1016/j.corsci.2009.05.049

[24] Juttner, K. (1990) Electrochemical Impedance Spectroscopy (EIS) of Corrosion Processes on Inhomogeneous Surfaces. Electrochimica Acta, 35, 1501-1508. https://doi.org/10.1016/0013-4686(90)80004-8

[25] Lopez, D.A., Simison, S.N. and De Sanchez, S.R. (2005) Inhibitors Performance in $\mathrm{CO}_{2}$ Corrosion EIS Studies on the Interaction between Their Molecular Structure and Steel Microstructure. Corrosion Science, 47, 735-755.

[26] Li, X.H. and Mu, G.N. (2005) Tween-40 as Corrosion Inhibitor for Cold Rolled Steel in Sulphuric Acid: Weight Loss, Electrochemical Characterization, and AFM. Applied Surface Science, 252, 1254-1265. https://doi.org/10.1016/j.apsusc.2005.02.118

[27] Fouda, S.A. and Attia, A.A. (2014) Some Thiophene Derivatives as Corrosion Inhibitors for Carbon Steel in Hydrochloric Acid. Journal of Metallurgy, 2014, Article ID: 472040. https://doi.org/10.1155/2014/472040

[28] Zhang, F., Tang, Y.M., Cao, Z.Y., Jing, W.H., Wu, Z.L. and Chen, Y.Z. (2012) Performance and Theoretical Study on Corrosion Inhibition of 2-(4-Pyridyl)-Benzimidazole for Mild Steel in Hydrochloric Acid. Corrosion Science, 61, 1-9. https://doi.org/10.1016/j.corsci.2012.03.045

[29] Ramesh, S.V. and Adhikari, A.V. (2008) Quinolin-5-Ylmethylene-3-\{[8-(Trifluoromethyl)Quinolin-4-Yl]Thio\}Propanohydrazide as an Effective Inhibitor of Mild Steel Corrosion in $\mathrm{HCl}$ Solution. Corrosion Science, 50, 55-61. https://doi.org/10.1016/j.corsci.2006.06.035

[30] Eldesoky, A.M., Fouda, A.S., Bekheit, G.E. and Elsheikh, N.S. (2015) Adsorption and Corrosion Inhibition of Alkanna Tinctoria Extract (ATE) on Copper in $1 \mathrm{M}$ $\mathrm{HNO}_{3}$ Solution. International Journal of Advanced Research, 3, 991-1007.

[31] Abdallah, M. (2002) Rhodanine Azosulpha Drugs as Corrosion Inhibitors. Corrosion Science, 44, 717-728. https://doi.org/10.1016/S0010-938X(01)00100-7 
[32] Yadav, M., Sinhua, R.R., Sarkar, T.K. and Tiwari, N. (2015) Corrosion Inhibition Effect of Pyrazole Derivatives on Mild Steel in Hydrochloric Acid Solution. Journal of Adhesion Science and Technology, 29, 1690-1713.

https://doi.org/10.1080/01694243.2015.1040979

[33] Karthik, G. and Sundaravadivelu, M. (2013) Inhibition of Mild Steel Corrosion in Suphuric Acid Using Esomeprazole and the Effect of Iodide Ion Addition. ISRN Electrochemistry, 2013, Article ID: 403542. https://doi.org/10.1155/2013/403542

\section{Supplementary Material}

CCDC No. 1007670, 1015298 and 875789 contains the supplementary crystallographic data for this paper. These data can be obtained free of charge via http://www.ccdc.cam.ac.uk/data_request/cif (or from the Cambridge Crystallographic Data Centre, 12 Union Road, Cambridge CB2 1EZ, UK; fax: (+44)1223-336-033; or deposit@ccdc.cam.uk). 